\title{
Unilateral Extensive Myelinated Retinal Nerve Fiber Layer in a Child
}

\author{
Rafidah Saleh and Maimunah A. Muna’aim
}

\begin{abstract}
We are reporting a case of an incidental finding of an extensive Myelinated Retinal Nerve Fiber Layers (MRNFL) in a healthy 12-year-old Malay boy. The child did not complain of any blurring of vision until he accidentally closed his seeing eye. On examination, the right visual acuity was $6 / 6$ while the left visual acuity was $6 / 150$. There was no Relative Afferent Pupillary Defect (RAPD). The anterior segment was unremarkable. The fundus of the right eye was normal with a pink optic disc with CDR of 0.4, however, the left eye showed extensive MRNFL involving the whole fundus but sparing the macula. The subjective refraction of the right eye was Plano with $6 / 6$ vision, while the left was $-5.50 /-1.50 \times 50$ with a vision of $6 / 150$. Bjerrum of the right eye was normal but the left eye showed tunnel field at around 20 degrees with $2 \mathrm{~mm}$ target size. His Humphrey Visual Field (HVF) 30-2, for the right eye, was normal with MD -0.90 while the left eye showed a generalized reduction of the field with $\mathrm{MD}$ of $\mathbf{- 2 0 . 2 3}$. Optical Coherence Tomography (OCT) of the right eye was normal while the affected eye showed thickening of the RNFL at the peripheral. The other layers of the retina and the foveal region of anatomy were somehow preserved. The axial length of the right eye was $24.10 \mathrm{~mm}$ while the left eye was $28.06 \mathrm{~mm}$. MRNFL is a benign condition. It is commonly seen as a streak of whitish patch starting from the optic disc extending to the retina following the arcuate nerve fiber layer pattern, however, extensive myelinated retinal nerve fiber layer involving the whole retina was not very common and usually associated with amblyopia, axial myopia, and squint. Even though mostly benign and solitary, MNFL can be associated with other systemic condition, therefore, clinicians must rule out other systemic diseases.
\end{abstract}

Index Terms - Amblyopia, Anisometropia, child, myelin sheath, Optical Coherence Tomography.

\section{CASE REPORT}

We are reporting a case of an incidental finding of an extensive myelinated Retinal Nerve Fiber Layers (RNFL) in a healthy 12-year-old Malay boy. The child did not complain of any blurring of vision until this year, he accidentally closed his seeing eye. The right visual acuity was $6 / 6$ while the left visual acuity was $6 / 150$ or roughly Finger Counting at 1 foot. Both Intraocular pressure (IOP) was normal. The eyes were orthophoric and there was no Relative Afferent Pupillary Defect (RAPD). On examination the anterior segment was unremarkable. The fundus of the right eye was normal with a pink optic disc with CDR of 0.4 , however, in the left eye, the Optic Disc was pink but severely obscured by the extensive whitish pale fibers starting from the disc, extending to the peripheral fundus, following the arcuate RNFL pattern but sparing the macula. There were no other abnormalities seen at the retina (Fig.1).

Published on August 16, 2020.

Rafidah Saleh, (MD UKM), (MSurg Ophthal UKM), Fellowship Medical Retina Bern, Malaysia.

(corresponding e-mail: rafidahsaleh@yahoo.com)

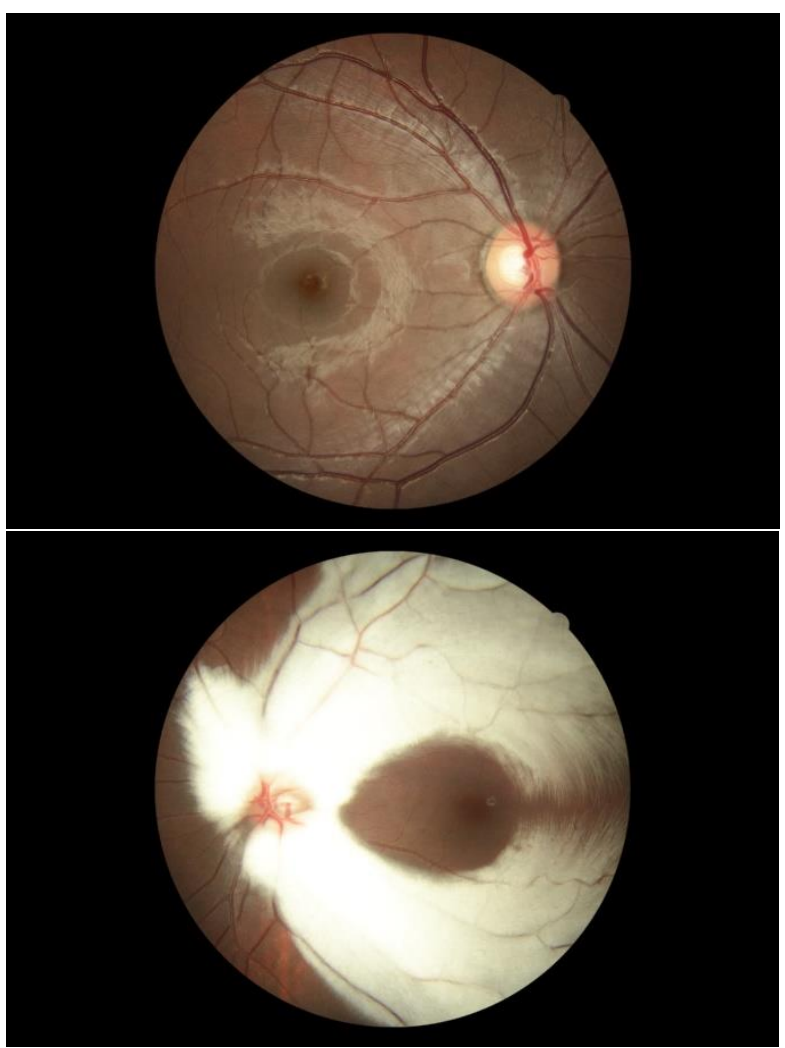

Fig. 1. Colored photo of the right eye showed the fundus of the right eye was normal with a pink optic disc with CDR of 0.4, however, in the left eye, the Optic Disc was pink but severely obscured by the extensive whitish pale fibers starting from the disc, extending to the peripheral fundus, following the arcuate RNFL pattern but sparing the macula.

The subjective refraction of the right eye was Plano with $6 / 6$ vision, while the left was $-5.50 /-1.50 \times 50$ with a vision of $6 / 150$. Bjerrum of the right eye was normal but the left eye showed small tunnel field at around 20 degrees with $2 \mathrm{~mm}$ target size (Fig. 2).

His Humphrey Visual Field (HVF) 30-2, for the right eye, was normal with MD -0.90 while the left eye showed a generalized reduction of the field with MD of -20.23 . Spectral-Domain Optical Coherence Tomography (OCT) of the right eye was normal while the affected eye showed thickening of the RNFL at the peripheral, so thick that it cast a long shadow obscuring the retinal layers below it. The foveal region anatomy was somehow preserved (Fig. 3).

SD-OCT RNFL of both Optic Nerve Head showed normal thickness over the right side while severely thickened over the left side (Fig. 4).

The axial length of the right eye was $24.10 \mathrm{~mm}$ while the left eye was $28.06 \mathrm{~mm}$ showed a severely anisometropic eye

Maimunah A. Muna'aim, Universiti Sains Islam Malaysia, Malaysia. 
with dense amblyopia.

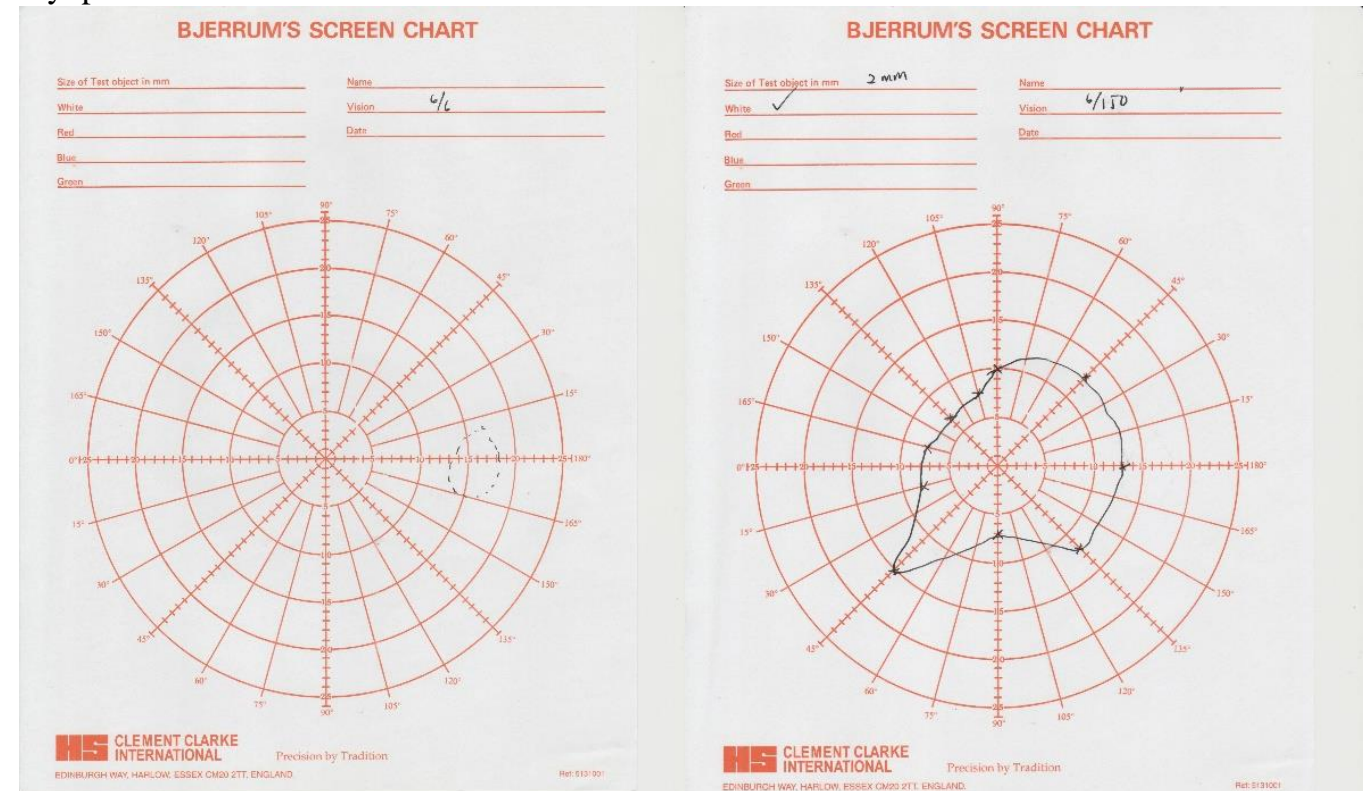

Fig. 2: The right Bjerrum Chart was normal while the left Bjerrum showed small tunnel vision about 20 degrees central.
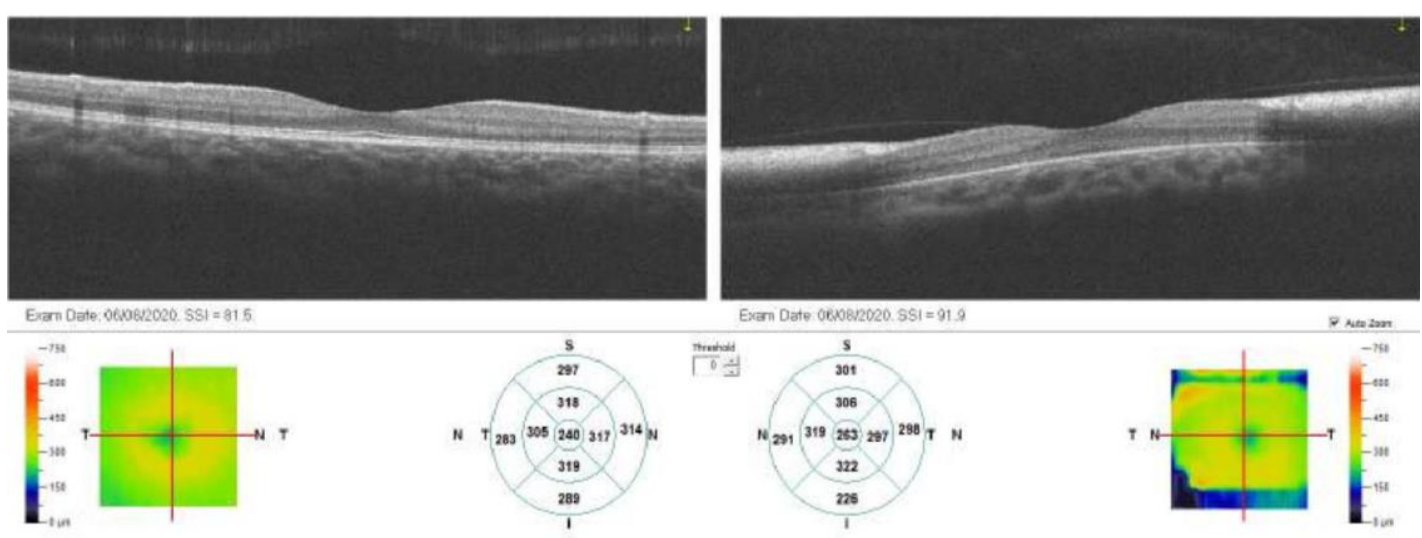

Fig. 3. SD-OCT Retina Map OU report showed the right eye with normal retinal anatomy while the left eye showed thickening of the peripheral retina, so thick that it casts a long shadow obscuring the layers below it.

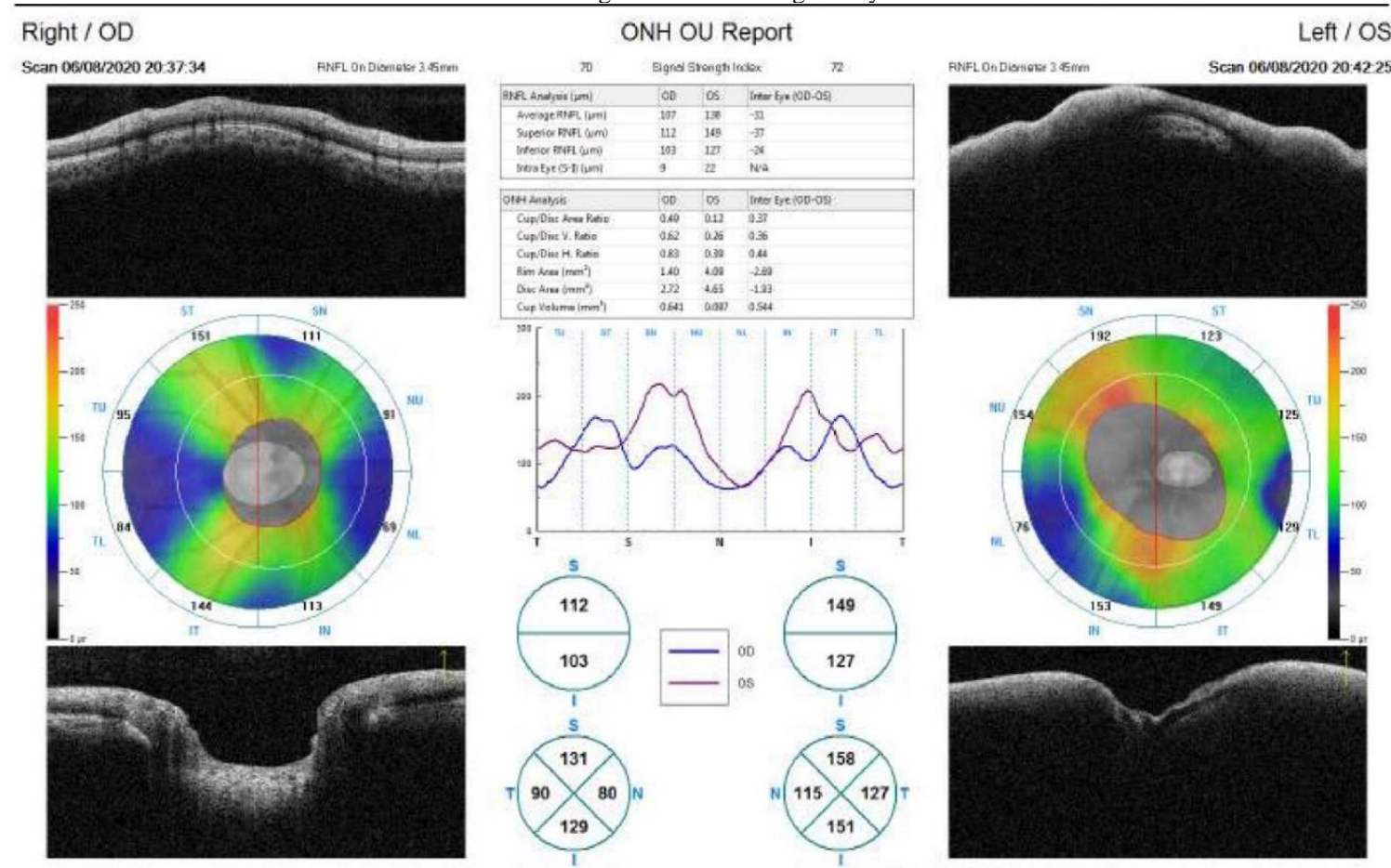

Fig. 4. SD-OCT RNFL of both Optic Nerve Head showed normal thickness over the right side while severely thickened over the left side. 


\section{DISCUSSION}

In the case discussed above, the child was found to have an extensive myelinated RNFL associated with severe anisometropia and dense amblyopia. This condition is congenital and benign. It is found in 0.57 to $1 \%$ of the population. [1] On funduscopy, it usually appeared as white patches following the arcuate pattern of RNFL. [2] In terms of patterns, there was a lot of variety in its locations. It can either present in all quadrant of the retina or mainly in the superior and inferior quadrant. The common location was juxtapapillary with the mean largest base diameter was $2.7 \mathrm{~mm}$ with the mean of three clock hours in size [3]. Extensive myelinated RNFL involving the whole fundus is not common and usually associated with amblyopia, axial myopia, and squint. On imaging such as red-free, it is seen as white. The whitish opaque appearance is due to its high lipid content inside the myelin sheath. On Optical Coherence Tomography (OCT) the RNFL appears thickened at the periphery. On the Fundus Autofluorescence (FAF) it appears dark and also causes blockage on Fluorescein Angiography. Even though it is usually solitary and non-progressive, it may be associated with a lot of systemic conditions such as optic disc drusen [4], optic nerve hypoplasia [5], keratoconus [6], Leber's hereditary optic neuropathy [7] and optic nerve glioma as well as myopia, anisometropia, and amblyopia syndrome [8]. Therefore, one must think of its associated features before simply discharging the patient. In our patient, the main cause of poor vision was the densely myelinated fibers and the severe anisometropia. If he would have presented earlier, patching therapy with full optical cycloplegic correction using contact lens might be possible since there is a little bit of tunnel vision left in that affected eye, however, the prognosis is still very poor in this type of case in view of the extensive myelination.

\section{ACKNOWLEDGMENT}

Source of financial support: This paper did not receive any specific grant from funding agencies in the public, commercial, or not-for-profit sectors.

\section{REFERENCES}

[1] T. Kodama, S. Hayasaka and T. Setogawa, "Myelinated retinal nerve fibers: prevalence, location and effect on visual acuity," Ophthalmologica, vol 200, pp. 77-83, 1990.

[2] H.L. Ramkumar, R. Verma, H.A. Ferreyra, S.L. Robbins, "Myelinated Retinal Nerve Fiber Layer (RNFL): A Comprehensive Review," International Ophthalmology Clinics, vol 58, No.4, pp. 147-156, 2018.

[3] R. Rao, E. Turkoglu, E.A.T Say, C.L. Shields, "Clinical Features, Imaging, and, Natural History of Myelinated Nerve Fiber Layer," RETINA, vol. 39, pp. 1125-1132, 2019.

[4] R. Duval, K. Hammamji, M. Aroichane, et al, "Acquired myelinated nerve fibers in association with optic disk drusen," J AAPOS, vol. 14 pp. 544-547. 2010.

[5] B.H. Ali, S. Logani, K.L. Kozlov, et al., "Progression of retinal nerve fiber myelination in childhood," Am J Ophthalmol," vol. 118, pp. 515517, 1994.

[6] M. Leozappa, S. Ciani, T.M. Ferrari, "Corneal cross-linking for the treatment of keratoconus in a patient with an ipsilateral myelinated retinal nerve fiber layer," Case Rep Ophthalmol, vol. 2, pp. 99-104, 2011.

[7] J.J. Gicquel, B. Salama, M. Mercié, et al., "Myelinated retinal nerve fibers loss in Leber's hereditary optic neuropathy," Acta Ophthalmol Scand, vol 83, pp. 517-518, 2005.

[8] B.R. Straatsma, J.R. Heckenlively, R.Y. Foos and J.K. Shahinian, "Myelinated retinal nerve fibers associated with ipsilateral myopia, amblyopia, and strabismus," Am J Ophthalmol, vol 88, pp. 506-510, 1979.

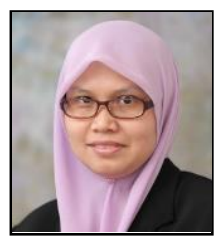

Dr. Rafidah Saleh was born in Negeri Sembilan, Malaysia on the 16th of May 1977. She graduated as a Medical Doctor (M.D UKM) from Universiti Kebangsaan Malaysia (UKM) in 2001 and started working in the Kuala Lumpur General Hospital thereafter.

Dr. Saleh joined Universiti Putra Malaysia (UPM) as a trainee lecturer in the year 2006 and then started her Masters in Ophthalmology in UKM. She finished her Masters (M.Surg Ophthal. UKM) in 2010 then started teaching undergraduates in UPM while practicing Ophthalmology. Five years later she started her journey of Subspecialty Fellowship in the field of Medical Retina in Bern Inselspital, Switzerland for a year under the supervision of Professor Sebastian Wolf. Currently, she continued her service in the newly built Universiti Putra Malaysia Teaching Hospital (HPUPM) in Serdang, Malaysia. Her specialties are Diabetic Retinopathy, AgeRelated Macular Degeneration (ARMD), and other retinal pathologies. Her most noted publication includes R Saleh, A Karpe, M Zinkernagel, and M Munk, "Inner retinal layer change in glaucoma patients receiving anti-VEGF for neovascular age-related macular degeneration," Graefes Arch Clin Exp Ophthalmol, vol. 255, no. pp. 817-824, Apr 2017. Other than that she also co-writes a few more other papers on the general Ophthalmology field.

Dr. Saleh is a registered doctor under the National Specialist Register (NSR), a member of the Malaysian Medical Association (MMA), Malaysian Society of Ophthalmology (MSO) which is an active member of the International Council of Ophthalmology (ICO).

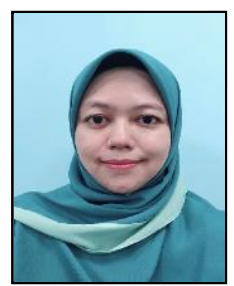

Dr. Maimunah Abdul Muna'aim was born on 24 Nov 1977 in Perlis, Malaysia. She graduated as a Medical Doctor from Universiti Kebangsaan Malaysia (M.D UKM) in 2002. After that she worked with the government hospital then later she joined Universiti Putra Malaysia (UPM) as a trainee lecturer. She later completed her Masters in Ophthalmology (Doct of Ophthalmology UKM) in 2013 and then started teaching the undergraduates thereafter. A few years later she changed the employer and moved to Universiti Sains Islam Malaysia (USIM) in Nilai, Malaysia until now.

Dr. Munaaim is deeply interested in Neuro-ophthalmology and planned to subspecialize in that field. In her current university, she is actively involved in the prevention of blindness projects in the community. She has published a book entitled "Polisi Perkhidmatan Klip Mobile Klinik Mata Bergerak, Medical and Health Sciences Faculty, Univerisiti Sains Islam Malaysia." ( The policy of Clip-Mobile Eye Clinic in Medical and Health Sciences Faculty, Univerisiti Sains Islam Malaysia ). A few of her notable publications are N. Omar, M.A. Muna'aim, R. Saleh, Z.M. Kasim, M.M. Isa, “An 8-year Retrospective Review of Microbial Keratitis in A Secondary Referral Centre in Malaysia," Malaysian Journal of Medicine and Health Sciences, vol. 13, no. 2, pp. 45-57, June 2017. She and her team product named "DROP AIDE" has also secured one Gold Medal in the National Level Contest for medical students projects held by the Ministry of Education in 2019. 